\title{
Evanghélia Stead, Le monstre, le Singe et le Fœtus
}

\section{Ida Merello}

\section{Q OpenEdition}

\section{Journals}

\section{Edizione digitale}

URL: http://journals.openedition.org/studifrancesi/35037

DOI: 10.4000/studifrancesi.35037

ISSN: 2427-5856

\section{Editore}

Rosenberg \& Sellier

\section{Edizione cartacea}

Data di pubblicazione: 1 novembre 2005

Paginazione: 441

ISSN: 0039-2944

\section{Notizia bibliografica digitale}

Ida Merello, «Evanghélia Stead, Le monstre, le Singe et le Fœtus», Studi Francesi [Online], 146 (XLIX | II) | 2005, online dal 30 novembre 2015, consultato il 18 avril 2021. URL: http://journals.openedition.org/ studifrancesi/35037 ; DOI: https://doi.org/10.4000/studifrancesi.35037

\section{Questo documento è stato generato automaticamente il 18 avril 2021.}

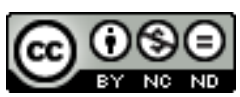

Studi Francesi è distribuita con Licenza Creative Commons Attribuzione - Non commerciale - Non opere derivate 4.0 Internazionale. 


\title{
Evanghélia Stead, Le monstre, le Singe et le Fotus
}

\author{
Ida Merello
}

\section{NOTIZIA}

EVANGHÉLIA STEAD, Le monstre, le Singe et le Fœtus, Genève, Droz 2004, pp. 602.

1 I tre elementi del titolo bene rappresentano, secondo l'autrice, l'immaginario decadente legato al darwinismo, l'evoluzionismo e l'embriologia. Scopo del volume è mostrare proprio come questa triade possa rendere conto della teratologia fin de siècle nei suoi aspetti estetici e sacrileghi.

Il ponderoso saggio, diviso in sette parti a loro volta suddivise in sezioni e corredato da una splendida biblio-iconografia, discute in prima battuta la definizione di decadenza, prendendone in esame tutte le implicazioni e tentando di isolare una «lingua della decadenza»: tentativo già oltre modo praticato, a livello di elenco di figure e di oggetti, ma qui indagato minuziosamente a partire dal glossario di Plowert (1888, Petit glossare pour servir à l'intelligence des auteurs décadents et symbolistes) fino alla ricerca nei testi delle diverse sfumature del concetto stesso di «langue corrompue»; in tal modo la sindrome di decadenza viene verificata anche attraverso la mostruosità linguistica. L'autrice ci conduce quindi facilmente dalla mostruosità della lingua e del corpo a quella blasfema che registra la morte di Dio, prima di passare alla definizione del mostro, con attenzione in un primo tempo al rapporto del mostruoso con la letteratura - facendo perno sul saggio Le Monstre di Huysmans, che sottolinea la preponderanza dell'immagine nella letteratura fine secolo -; in un secondo tempo analizzando i suoi sviluppi mitologici, con particolare riferimento alla Chimera e al basilisco. Lo studio della Chimera favorisce lo slittamento alla riflessione sulla femme fatale, per il rapporto di contiguità tra la Chimera e la figura femminile che in molte iconografie la cavalca. La terza parte è perciò interamente dedicata all'accostamento della donna all'animale 
nell'uso degli aggettivi, nell'elaborazione trattatistica, nei saggi scientifici, nella pittura e infine nei racconti.

3 Un'altra sezione è dedicata ai mostri da baraccone e alla loro rappresentazione letteraria. Prima di affrontare gli altri due elementi del titolo, le Singe e le Fœtus, l'estensore prende perciò in considerazione il mostro di natura, partendo dai testi fin de siècle sul mostro, dai repertori degli specialisti di scienze naturali fino ai testi letterari, per mostrare come la mostruosità, sia animale che vegetale, rappresenti una delle principali ossessioni della decadenza. La scimmia, presente nei Contes de la décadence romaine di Richepin, viene a sua volta trattata come mostro dagli autori dell'epoca: rimessa di moda dal darwinismo, diventa oggetto in pittura come in letteratura di scene di esplicita perversione sessuale, attraverso la caricatura e la riscrittura mitica, ma viene utilizzata molto spesso anche come metafora dello scrittore e dell'artista.

4 Lo steso feto, il cui studio è stato analogamente riproposto dagli studi sull'evoluzionismo, viene recuperato nei suoi aspetti di mostruosità e utilizzato spesso come metafora della paura decadente dell'impotenza e strumento di trasformazione estetica del difforme. 